\title{
Patología infecciosa importada en síndrome febril de origen desconocido en niño inmigrante: 2 casos
}

\author{
Imported infectious diseases in fever of unknown \\ origin in migrant children: 2 cases
}

\author{
M. Ruiz Goikoetxea, R. Urabayen, M. Herranz, L. Moreno, F.J. Gil, E. Bernaola
}

\section{RESUMEN}

El auge de los movimientos migratorios ha aumentado la incidencia de enfermedades infecciosas infrecuentes en nuestro medio. Ante la presencia de un proceso febril en niños procedentes de áreas endémicas, se deben descartar en primer lugar enfermedades infecciosas importadas. Presentamos dos casos de fiebre tifoidea en niños inmigrantes, diagnosticados recientemente en nuestro centro. Ambos procedían de países con alta prevalencia de la enfermedad e ingresaron para estudio de fiebre de origen desconocido. Los dos pacientes residían en nuestro país desde hacía menos de un mes. El aislamiento de bacilo gran negativo en los hemocultivos fue clave para llegar al diagnóstico etiológico. En los dos casos se instauró antibioterapia endovenosa y se negativizaron tanto los hemocultivos como los coprocultivos de forma previa al alta. En la actualidad los dos niños se encuentran libres de enfermedad.

Palabras clave. Fiebre tifoidea. Niño. Inmigrante. Salmonella entérica. Fiebre de origen desconocido.

\begin{abstract}
The increase in migratory movements has increased the incidence of infectious diseases that were infrequent in our setting. In the presence of fever in children from endemic areas, imported infectious diseases must be ruled out in the first place. We present two cases of typhoid fever in immigrant children, recently diagnosed in our centre. Both from countries with a high prevalence of the disease were admitted for study of fever of unknown origin. The two patients had been living in our country for less than one month. Isolation of the gram-negative bacillus in the blood cultures provided the key for reaching the etiological diagnosis. In both cases endovenous antibiotherapy was established and both the blood cultures and stools became negative before discharge. At present the two children are free of the disease.
\end{abstract}

Key words. Typhoid fever. Children. Immigrant. Salmonella enterica. Fever of unknown origin.
Servicio de Pediatría

Complejo Hospitalario de Navarra

Recepción: 1 de septiembre de 2011

Aceptación provisional: 19 de diciembre de 2011

Aceptación definitiva: 10 de febrero de 2012

\section{Correspondencia:}

Maite Ruiz Goikoetxea

Servicio de Pediatría

Complejo Hospitalario de Navarra

E-mail: maite.ruiz.goikoetxea@navarra.es 


\section{INTRODUCCIÓN}

La fiebre tifoidea (o fiebre entérica) es una enfermedad infecciosa de distribución mundial, endémica en Asia centro-meridional y sudoriental, África y Latinoamérica. La mejora de las condiciones socio-sanitarias durante el siglo pasado la han convertido en una enfermedad relativamente excepcional en nuestro medio. Sin embargo, en países en desarrollo la enfermedad es muy prevalente y en ocasiones no está exenta de mortalidad debido a la falta de agua potable, la escasa cobertura vacunal y la no universalidad de la atención sanitaria. La infección por Salmonella tiphy origina aproximadamente 20 millones de casos de fiebre tifoidea /año y 200.000 muertes ${ }^{1,2}$. En nuestro país, debido al aumento de los movimientos migratorios en los últimos años, se ha experimentado un repunte en la incidencia de la enfermedad. En España la tasa de infección es de 0,21 por cada 100.000 habitantes $^{3}$. Es necesario un alto índice de sospecha de la enfermedad con el fin de llegar a un diagnóstico etiológico.

\section{CASOS CLÍNICOS}

Caso 1. Varón de 14 años remitido al servicio de Urgencias de Pediatría de un hospital terciario por presentar fiebre de una semana de evolución. El paciente, de origen peruano, residía en Navarra desde hacía 15 días. Refería fiebre vespertina $\left(39,5^{\circ} \mathrm{C}\right)$, que se acompañaba de cefalea frontal. No presentaba vómitos, deposiciones diarreicas, sintomatología miccional, ni clínica respiratoria. Antecedente de contacto con gatos domésticos durante su estancia en Perú. El niño estaba vacunado frente a tuberculosis, polio oral (3 dosis), sarampión y difteria (3 dosis). Los antecedentes personales carecían de interés. El día previo a la consulta en urgencias, se había iniciado estudio del proceso de forma ambulatoria: se solicitaron analítica sanguínea, radiografía de tórax y urocultivo. La analítica mostraba 4.000 leucocitos con neutrófilos $76 \%$, un leve aumento de las transaminasas y de la proteína $\mathrm{C}$ reactiva (PCR) de hasta $9 \mathrm{mg} / \mathrm{dL}$. En la radiografía de tórax no se objetivaron alteraciones y el urocultivo fue negativo. La exploración física realizada en el servicio de Urgencias resultó anodina.

Se reevaluó al paciente a las 72 horas y ante la persistencia de la fiebre ingresó para estudio. En la exploración física se detectó únicamente una discreta hiperemia faríngea. Se extrajo hemocultivo y se repitió la analítica sanguínea que mostraba 5.100 leucocitos con una fórmula normal, 161.000 plaquetas, PCR 17,8 mg/dL, procalcitonina (PCT) $0,5 \mathrm{ng} / \mathrm{mL}$ y ligero aumento de alaninatransaminasa $80 \mathrm{U} / \mathrm{L}$. Se completó el estudio con realización de una ecografía abdominal que resultó normal y una ecocardiograma en el que se apreció una insuficiencia tricuspídea funcional con morfología cardíaca normal. El estudio de inmunidad resultó normal. Las serologías para Brucella, Rickettsia conorii, Bartonella, Epstein-Barr y VIH fueron negativas. No se realizó estudio de gota gruesa al no proceder de región endémica para el Plasmodium. El paciente presentó inmunidad para VEB, rubéola, CMV, VHA y VHB. Tanto el urocultivo, el estudio de parásitos en heces y el coprocultivo recogidos al ingreso fueron negativos. El Mantoux fue $0 \mathrm{~mm}$. A las 48 horas del ingreso se aisló Salmonella typhi en hemocultivo. El antibiograma demostró sensibilidad a ampicilina, cefotaxima y ciprofloxacino, por lo que se instauró antibioterapia con cefotaxima endovenosa. Ante la persistencia de picos febriles diarios tras una semana de tratamiento, se modificó la pauta antibiótica y se sustituyó cefotaxima por la combinación de levofloxacino endovenoso y azitromicina oral. Tras la modificación de la terapia antiinfecciosa, se produjo una significativa mejoría clínica con remisión de la fiebre al tercer día de la nueva combinación de antibioterapia (11 $1^{\mathrm{o}}$ día de ingreso). Los cultivos de control de sangre, orina y heces fueron negativos. Los controles analíticos seriados evidenciaron una normalización progresiva de las pruebas de función hepática y negativización de los reactantes de fase aguda. Tras 14 días de ingreso, una vez finalizado el tratamiento antibiótico, el paciente fue dado de alta. Posteriormente, fue seguido en consulta de forma periódica encontrándose asintomático desde el punto de vista clínico y analítico.

Caso 2. Niña de 2 años y 8 meses procedente de Senegal, que ingresó a las 24 horas de su llegada a España para estudio de fiebre de una semana de evolución. El cuadro se acompañaba de 5-6 deposiciones diarreicas diarias. En la anamnesis los padres referían encontrar a la niña apática, hiporéxica y con tendencia al sueño. Previamente a su llegada a España, había recibido una dosis de artesonato por sospecha de paludismo. Entre los antecedentes personales, destacaba una hemiparesia izquierda y crisis comiciales consecuencia de una infección por Plasmodium falciparum a los 13 meses de edad. El calendario vacunal era desconocido. En la exploración física presentaba fiebre $\left(38,8^{\circ} \mathrm{C}\right)$ y hepatomegalia $(2 \mathrm{~cm})$. La analítica sanguínea inicial mostró: 
hemoglobina $10,8 \mathrm{~g} / \mathrm{dL}$, hematocrito $31,9 \%$, volumen corpuscular medio $71,8 \mathrm{fl}$, leucocitos 3.100 con fórmula normal, plaquetas 106.000, PCR 24,1 $\mathrm{mg} / \mathrm{dL}$, PCT $8 \mathrm{ng} / \mathrm{mL}$, alaninatransaminasa 57 U/L y sodio $130 \mathrm{mmol} / \mathrm{L}$. No se observaron parásitos en sangre y el estudio de gota gruesa resultó negativo en tres ocasiones. Se realizó radiografía de tórax, ecografía abdominal, sedimento urinario y urocultivo sin apreciarse alteraciones significativas. Al ingreso se instauró antibioterapia endovenosa empírica con cefotaxima. En el hemocultivo y coprocultivo recogidos previamente al inicio del tratamiento, se aisló Salmonella typhi sensible a ampicilina, cefotaxima, ciprofloxacino y trimetoprim-sulfametoxazol. Dados los antecedentes de la paciente se realizó electroencefalograma que mostraba actividad epileptiforme en regiones anteriores durante el sueño, y se inició entonces tratamiento con levetiracetam. Se completó estudio de la epilepsia con una resonancia magnética cerebral, en la que se observó leucomalacia atrófica y atrofia cortical supratentorial ambas de predominio occipital. Se recogieron hemocultivos y coprocultivos de control en pico febril el $5^{\circ}$ día de inicio de antibioterapia, siendo ambos negativos. Una vez completado el tratamiento (tras 14 días de antibioterapia), los controles analíticos eran normales exceptuando elevación de velocidad de sedimentación glomerular $87 \mathrm{~mm} / \mathrm{h}$. La paciente se encontraba asintomática desde el punto de vista infeccioso y fue dada de alta al domicilio. Desde entonces recibe tratamiento anticomicial y es controlada regularmente en consultas externas de Neuropediatría.

\section{DISCUSIÓN}

La fiebre tifoidea es endémica en África (tasa anual de 10-100 por cada 100.000 habitantes) ${ }^{1}$, en Asia centro-meridional y sudoriental, y Latinoamérica. En la mayoría de los casos existe un antecedente de viaje a un país endémico con un intervalo inferior a 30 días $^{2,4}$. En España se trata de una enfermedad generalmente importada, y la tasa de hospitalización es de 0,31 por cada 100.000 habitantes $^{5}$. Es una enfermedad de declaración obligatoria, por lo que los dos casos fueron notificados a las autoridades pertinentes.

La infección está causada por el bacilo gram negativo Salmonella enterica, siendo más frecuente el serotipo typhi que el paratyphi ${ }^{4}$, siendo el primer serotipo responsable del 93\% de hospitalizaciones en Espa- ña ${ }^{5}$. Los dos sujetos atendidos en nuestro centro procedían de países en desarrollo endémicos y se detectaron antes de pasar 15 días desde su llegada a España. En ambos, la infección fue causada por el serotipo typhy.

El reservorio es exclusivamente humano; el contagio se produce a partir de enfermos convalecientes (excreción de bacilos en heces hasta 3 meses tras la curación) o de portadores sanos (colonización biliar superior a un año en el 1\% de los pacientes, sobre todo mujeres). La transmisión de la enfermedad es fecal-oral, por ingestión de alimentos o agua contaminados, consecuencia de defectuosas condiciones higiénico-alimentarias ${ }^{4}$. En nuestros dos casos no pudo detectarse la fuente de contagio. Se dedujo que la infección se debió a la ingesta de alimentos o agua contaminados ya que ninguno de los familiares tuvo síntomas de la enfermedad.

La infección presenta un periodo de incubación de 3 a 21 días. La manifestación clínica inicial más habitual comprende fiebre alta (superior a $40{ }^{\circ} \mathrm{C}$ la primera semana), con cuadro prodrómico de malestar general, mialgias, cefalea, y sintomatología digestiva (dolor abdominal, anorexia, estreñimiento/diarrea...). Los dos casos registrados en nuestro centro consultaron por fiebre persistente. En ambos casos se planteó diagnóstico diferencial con paludismo, sepsis por diferentes microorganismos, tuberculosis, hepatitis aguda, mononucleosis infecciosa, enfermedad por arañazo de gato, tifus y cuadro gripal (puesto que coincidió con periodo epidémico). No obstante en la segunda paciente, el antecedente de un caso de fiebre tifoidea en el servicio permitió acelerar el diagnóstico.

Durante la fase de estado ( $2^{\mathrm{a}}-4^{\mathrm{a}}$ semana) persiste la fiebre, hepatoesplenomegalia y clínica digestiva. Aproximadamente un tercio de los pacientes presentan el exantema conocido como roséola tifoidea; un exantema maculo-papuloso no pruriginoso con lesiones de color salmón que cursa en brotes en tórax y abdomen. En el primer caso, el paciente desarrolló lesiones dérmicas característica mientras que la segunda niña únicamente presentó deposiciones diarreicas. 
A partir de la $3^{\text {a }}-4^{\mathrm{a}}$ semana de evolución sin tratamiento empeora la clínica digestiva y el aspecto tóxico del paciente, persistiendo la fiebre. Pueden aparecer complicaciones sistémicas como miocarditis, peritonitis, hemorragias intestinales síntomas neuropsiquiátricos (obnubilación, delirium, meningismo). Estas complicaciones son más frecuentes en lactantes. Las convulsiones son frecuentes en niños menores de 5 años $^{2}$. La segunda paciente presentaba un cuadro de decaimiento importante (padres referían un empeoramiento claro respecto a su estado basal), que según la historia de la enfermedad no era achacable al cuadro infeccioso (fue diagnosticada en la primera semana del cuadro). La paciente presentaba secuelas cognitivas y motoras consecuencia de la malaria cerebral que padeció en la época de lactancia. Sin embargo, el inicio de la antibioterapia supuso una mejoría en el nivel de conciencia de la niña.

En los dos casos se objetivaron cifras de hemoglobina y plaquetas en límites normales en los primeros días de infección. La presencia de leucopenia y/o eosinopenia junto con hipertransaminasemia, orientaban el diagnóstico en el contexto de cuadro compatible. El aislamiento del microorganismo en hemocultivo es el gold estándar del diagnóstico de fiebre entérica, con un valor predictivo positivo de entre el $60-80 \%$, siendo la sensibilidad superior durante la primera semana de enfermedad. La sensibilidad aumenta en el cultivo de medula ósea (80-95\%) incluso después de iniciada la antibioterapia ${ }^{2,6}$. La serología demuestra que el nivel de anticuerpos aglutinantes frente a los antígenos $\mathrm{O}$ y $\mathrm{H}$ puede ser positiva a partir del séptimo día de enfermedad. Su utilidad como diagnóstico de la enfermedad está muy discutida, ya que la sensibilidad, especificidad y VPP poseen una gran variabilidad geográfica, sobredimensionando la magnitud de la infección en áreas endémica, puesto que existe un aumento de anticuerpos frente los antígenos $\mathrm{O}$ y $\mathrm{H}$, debido a infecciones subclínicas por Salmonella y otras enterobacterias ${ }^{1,2,6}$. Se ha desarrollado PCR para detección de Salmonella typhy en sangre, pero su utilización está poco extendida. En los dos pa- cientes se aisló Salmonella typhy en hemocultivos y coprocultivos previos al inicio de antibioterapia y no se solicitaron otros estudios serológicos complementarios.

Cerca del $10 \%$ de los pacientes no tratados pueden excretar Salmonella typhy en las deposiciones durante 3 meses y entre el uno y el $4 \%$ pueden convertirse en portadores crónicos (durante un año aproximadamente $)^{2}$. Es necesario aislar de forma adecuada a los enfermos, los portadores y los convalecientes hasta la obtención de tres coprocultivos negativos. La mortalidad sin tratamiento alcanza cifras de hasta el $15 \%$ en países en vías de desarrollo, siendo la tasa de mortalidad del $0,03 \%$ tras instauración del tratamiento antibiótico correcto ${ }^{4,5}$. En Europa y Norteamérica las cepas de Salmonella son sensibles a los antibióticos empleados habitualmente. Sin embargo, las cepas encontradas en los países endémicos han desarrollado un elevado índice de resistencias ${ }^{7}$. A pesar de que existe fuerte evidencia en la eficacia de fluoroquinolonas en el tratamiento de la enfermedad, su uso está limitado en pediatría ${ }^{8}$. Dado que las cefalosporinas de tercera generación son el tratamiento de primera línea en niños, en ambos pacientes se inició tratamiento con cefotaxima. En el primer caso (paciente de 14 años) ante la persistencia de la fiebre a pesar del tratamiento con dosis correctas de ceftriaxona, ésta se sustituyó por terapia combinada de azitromicina y levofloxacino.

Debido al mecanismo principal de la infección, es importante reforzar la educación higiénica-dietética de los padres de los pacientes que regresan a sus países de origen de forma esporádica. El consumo de agua embotellada, la higiene en la preparación de los alimentos (fundamentalmente lavado de manos) y evitar el consumo de carnes crudas reducen de forma significativa la transmisión ${ }^{2,4,9}$. Las vacunas actuales presentan entre una efectividad del $70-90 \%$. Existen en la actualidad tres preparados comercializados seguros y eficaces. Dos vacunas a base de polisacáridos por vía parenteral (una aprobada para mayores de 2 años y la otra para mayores de 6) que producen seroconversión en el $95 \%$ de los vacunados, aunque los títulos de an- 
ticuerpos disminuyen en los años posteriores, con lo cual puede ser necesaria la reevacunación. La vacuna atenuada oral está aprobada en niños mayores de 6 años, posee una eficacia del $75 \%$ a las $2-3$ semanas de la vacunación y requiere revacunación anual en caso de reexposición.

En conclusión, ante un proceso febril de origen desconocido en pacientes procedentes de áreas endémicas (inmigrantes y viajeros internacionales) en el último mes y medio es prioritario descartar patología infecciosa como primera sospecha. En los pacientes afectos de fiebre tifoidea no respondedores al tratamiento convencional, se debe tomar una decisión individualizada según las características de los pacientes valorando como alternativa terapéutica las fluoroquinolonas.

Es fundamental el conocimiento de este tipo de enfermedades por parte de los pediatras tanto para el enfoque adecuado del planteamiento diagnóstico, así como para recomendar las medidas de prevención de la enfermedad en futuros viajes a países endémicos.

\section{BIBLIOGRAFÍA}

1. Mweu E, English M. Typhoid fever in children in Africa. Trop Med Int Health 2008; 13: 532-540.
2. Parry CM, Hien TT, Dougan G, White NJ, FARRAR JJ. Typhoid fever. N Engl J Med 2002 28; 347:1770-1782.

3. Hernández Cabrera M, Pérez Arellano JL. Fiebre tifoidea En: Vacunas CAd, editor. Manual de vacunaciones en pediatría. 4 ed. Bilbao: Asociación Española de Pediatría; 2008, p. 425438.

4. Lynch MF, Blanton EM, Bulens S, Polyak C, VoJDANI J, StEvenson J et al. Typhoid fever in the United States, 1999-2006. Jama 2009 26; 302: 859-865.

5. Gil R, Alvarez JL, Gomez C, Alvaro A, Gil A. Epidemiology of typhoid and paratyphoid fever hospitalizations in Spain (1997-2005). Hum Vaccin 2009; 5: 420-424.

6. Kundu R, Ganguly N, Ghosh TK, Yewale VN, ShaH RC, SнAн NK. IAP Task Force Report: diagnosis of enteric fever in children. Indian Pediatr 2006; 43: 875-883.

7. Kundu R, Ganguly N, Ghosh TK, Yewale VN, Shah RC, SHAH NK. IAP Task Force Report: management of enteric fever in children. Indian Pediatr 2006; 43: 884-887.

8. Thaver D, Zaidi AK, Critchley J, Azmatullah A, MADNI SA, BHUTTA ZA. A comparison of fluoroquinolones versus other antibiotics for treating enteric fever: meta-analysis. BMJ 2009; 338: b1865.

9. Poch J, Montesdeoca A, Hernández Borges A, Aparicio Jl, Herranz M, López Almaraz R et al. Valoración del niño inmigrante. An Sist Sanit Navar 2006; 29 (Suppl. 1): 35-47. 
